\title{
Gürültü Bariyeri için Çevre Dostu Alternatif: Doğal Elyaf Takviyeli Kompozit Malzemeler
}

\author{
Burcu Karaca Uğural* \\ *Ege Üniversitesi, Mühendislik Fakültesi, Tekstil Mühendisliği Bölümü, İzmir, Türkiye, (ORCID: 0000-0002-7717-2076), burcu.karaca@ege.edu.tr \\ (International Conference on Design, Research and Development (RDCONF) 2021 - 15-18 December 2021)
}

(DOI: 10.31590/ejosat.1039332)

\begin{abstract}
ATIF/REFERENCE: Karaca Uğural, B. (2021). Gürültü Bariyeri için Çevre Dostu Alternatif: Doğal Elyaf Takviyeli Kompozit Malzemeler. Avrupa Bilim ve Teknoloji Dergisi, (32), 1006-1010.

$\ddot{O} z$

Son yıllarda, ürün-üretim döngülerinde sürdürülebilirlik yeşil mutabakat kapsamında üzerine en çok odaklanılan konulardan biridir. Kompozit malzemelerin kullanıldığı tüm sektörlerde çevre dostu malzemelerden üretilen ve geri dönüştürülebilir kompozitlere ilgi günden güne artmaktadır. Bu çalışma kapsamında, doğal elyaf takviyeli termoplastik kompozit malzemelerin akustik sektöründe kullanım potansiyeli incelenmiştir. Keten liflerinin tek doğrultuda yönlenmiş yerleşiminin sağlandığı keten/polipropilen tekyönlü prepreg yapılardan üretilen tabakalı kompozit malzemelerin ses yutum katsayısı ve ses iletim kaybı performansı ölçülmüştür. Alınan test sonuçları, keten/polipropilen tekyönlü prepreg yapılardan elde edilen tabakalı kompozit plakaların düz bir geometride kullanıldığ 1 durumda kapalı gözenekli bir yapı sergilediğini ve bu nedenle darbe doğuşlu seslerin izolasyonunda kullanım potansiyeli olduğunu göstermektedir.
\end{abstract}

Anahtar Kelimeler: keten elyaf, tek yönlü prepreg, termoplastik kompozit, akustik performans.

\section{Environmentally Friendly Alternative for Noise Barriers: Natural Fiber Reinforced Composite Materials}

\begin{abstract}
In recent years, sustainability in product-production cycles has been one of the most focused topics within the scope of the green deal. There is a growing interest in recyclable composites produced from environmentally friendly materials within all sectors where composite materials are used. In this study, the potential of natural fiber reinforced thermoplastic composite materials to be used in the acoustic sector was investigated. Sound absorption coefficient and sound transmission loss performance of laminated composite plates produced from flax/polypropylene unidirectional prepreg structures, in which flax fibers are arranged in one direction, were examined. The test results show that the laminated composite plates produced from flax/polypropylene unidirectional prepreg structures exhibit a closed-pore structure when used in a flat geometry and therefore have the potential to be used in the isolation of structure-born sound.
\end{abstract}

Keywords: flax fiber, unidirectional prepreg, thermoplastic composite, acoustic performance.

\footnotetext{
* Sorumlu Yazar: burcu.karaca@ege.edu.tr
} 


\section{Giriş}

Son y1llarda, ürün-üretim döngülerinde sürdürülebilirlik yeşil mutabakat kapsamında üzerine en çok odaklanılan konulardan biridir. Kompozit malzemelerin kullanıldığı tüm sektörlerde çevre dostu malzemelerden üretilen ve geri dönüştürülebilir kompozitlere ilgi günden güne artmaktadır. Coronet (Thermoplastic Composites Infrastructure Cooperation Network) tarafından “2025 Avrupası'nda Kompozitler” hakkında hazırlanan raporda; lif takviyeli kompozit malzemeler üretim kolaylığı, çevre yükü, performans vb. birçok açıdan değerlendirilmiş olup, sürdürülebilirlik bakımından geleceğin malzemesi olarak doğal elyaf takviyeli termoplastik esaslı kompozit malzemeler gösterilmiştir.

Doğal lifler arasında nispeten daha yüksek mekanik özelliklere sahip lignoselülozik gövde liflerinden keten ve kenevir lifleri, kompozit sanayinde büyük ilgi görmektedir (Avérous \& Le Digabel, 2006; Goutianos et al., 2006; Hautala et al., 2004; Holbery \& Houston, 2006; Liu et al., 2007; Misnon et al., 2014; Stuart et al., 2006; Summerscales et al., 2013; Yan et al., 2014). Odunsu kısmından ayrılan ve taranarak şerit haline getirilmiş lifler; lif demeti, iplik veya kumaş formunda kompozit sektöründe takviye elemanı olarak kullanılabilmektedir (Goutianos et al., 2006; Martin et al., 2014; Martin et al., 2016; Misnon et al., 2014; Shah et al., 2012; Zimniewska et al., 2012).

Keten ve/veya kenevir elyaf kullanılarak üretilen doğal elyaf takviyeli termoplastik kompozit malzemeler; hafif ve dayanıklı tasarımların düşük çevre yükü ile elde edilmesi kapsamında dikkat çekmektedir. Son yıllarda özellikle ulaştırma sektöründe araç hafifletme, spor ekipmanlarında titreşim sönümleme performansının iyileştirilmesi ve tüketiciye yönelik son ürünlerde çevre dostu tasarımların yapılması alanında kullanım bulmaktadir. ürün yaşam döngüsü sunan keten ve kenevir lifleri, aynı zamanda yapılarında bulunan ve lümen adı verilen boşluk sayesinde hem düşük özgül ağırlık değerleri hem de ses ve 1sı yalıtım performansları ile dikkat çekmektedir (Grohe, 2004; Hajj et al., 2011; Kymäläinen \& Sjöberg, 2008; Nick et al., 2002; Yang \& Li, 2012).

Ses yalıtımı, bir malzemenin her iki tarafında ses iletimini sınırlama işidir. Bu yalıtım genellikle, yoğun malzemeler ile ses dalgalarının hareketini zorlaştırma, dalgaların sönümlenmesi, daha az dalga hareketinin sağlanması ve hafif gözenekli malzemeler ile de ses dalgalarını absorpsiyonlama prensibine dayanir.

Akustik yalıtım sistemlerinde, doğal elyaf genellikle dokusuz yüzey (keçe) formunda ve gözenekli yapı sağlayacak şekilde kullanılmaktadır. Akustik yalıtım sistemleri için tasarlanan keten elyaf içeren keçelerde, genelde tekstil sektöründe kullanıma uygun olmayan veya tekstil sektöründeki işlem adımlarında oluşan atık elyaf kullanılmaktadır. Söz konusu keçelerde keten elyaf ile birlikte keten bitkisinin saplarından gelen odunsu parçalar da bulunabilir.

Hajj ve arkadaşlarının yaptığ çalışmada $2 \mathrm{~mm}$ ve $10 \mathrm{~mm}$ uzunlukta keten elyaf ile $5 \mathrm{~cm}$ kalınlığında keçeler üretilerek ses yutum katsayısı incelenmiştir. Söz konusu keçelerin ağırlıkça \%50'sini odunsu parçaların oluşturduğu ve keten elyafın poligonal kesitli odunsu kısımların ise bal peteği yapısında olduğu belirtilmiştir. Ses yutum katsayısının daha uzun keten elyaf içeren
Yenilenebilir tarımsal ürün olmaları sayesinde sürdürülebilir

keçelerde (10 mm), daha kısa keten elyaf içeren keçelere ( $2 \mathrm{~mm})$, kıyasla tüm frekans bandı için yaklaşık \%16 daha yüksek olduğu gözlenmiştir. Keten elyaf ile üretilen keçelerin 0.5-0.85 aralığında ses yutum katsayısı sağlayabildiği ve bu değerlerin piyasada en çok kullanılan ürünler (akustik poliüretan köpük ile taşyünü) ile benzer olduğu belirtilmiştir (Hajj et al., 2011).

Yang ve Li, yaptıkları çalışmada keten, ramie ve jüt elyaftan dokunan kumaşlar ile üretilen epoksi kompozitlerin akustik davranışlarını incelemiştir. Kompozit plakalar \%65 elyaf içerecek şekilde $3 \mathrm{~mm}$ kalınlığında üretilmiştir. Keten kumaşların gürültü azaltma katsayısı 0.65 ve ses yutum katsayısı 1000-2000 Hz frekans aralığında 0.8 olarak ölçülmüştür. Öte yandan, keten kumaş/epoksi ile üretilen kompozit plakaların ses yutum katsayısı ise $1000-2000 \mathrm{~Hz}$ frekans aralığında 0.18, 5000-6000 Hz frekans aralığında 0.4 olarak ölçülmüştür. Keten elyafın karbon ve cam elyafa kıyasla daha özgün akustik performans sergilediği belirtilmiştir (Yang \& Li, 2012).

Bu çalışmada, keten elyafin konvansiyonel keçe veya kumaş formunda bulunduğu kompozit plakalar yerine keten elyafin tek doğrultuda yönlendiği özel bir prepreg formunda bulunduğu kompozit plakalar kullanılmıştır. Kompozit plakalar, BPREG A.Ş. firmasının patente konu bir teknikle ürettiği keten elyaf takviyeli tekyönlü termoplastik prepreg yapıların belirli sayıda ve dizilimde sıcak pres altında birleștirilmesi ile elde edilmiştir. Kompozit plakalarda akustik performans incelemesi, TS EN ISO 10534-2 standardına uygun olarak empedans tüpü kullanılarak gerçekleştirilen akustik karakterizasyon testleri ile yapılmıştır.

\section{Materyal ve Metot}

\subsection{Kompozit Plaka Üretimi}

Doğal elyaf takviyeli kompozit malzeme üretiminde, keten liflerinin tek doğrultuda yönlenmiş yerleşiminin sağlandığ keten/polipropilen tekyönlü prepreg yapılar kullanılmıştır. Preimpregnated (önceden emprenye edilmiş) teriminin kısaltılmış hali olan prepreg terimi; matris polimerinin takviye malzemesi olan liflere kısmen veya tamamen tutunmasının sağlandığı ve kalıplanarak şekil almaya müsait ince tabakalar halindeki yarı mamul kompozit malzemeler için kullanılmaktadır. Çalışmada kullanılan keten/polipropilen tek yönlü prepreg yapılar, BPREG Kompozit ve Tekstil A.Ş. firmasından temin edilmiştir. EcoRein ${ }^{\circledR}$ UD ismi ile piyasada bulunan ürünler patente konu özel bir teknik ile üretilmektedir. Kompozit plaka üretiminde kullanılan keten/polipropilen tekyönlü prepreg yapı Şekil 1'de verilmiştir.

Keten/polipropilen tekyönlü prepreg yapıların çeşitli sayıda ve [0/90] dizilim ile üstüste yerleştirilmesi ve sicak press altında birleştirilmesiyle (Fontijne Grotnes Econ Lab 300) tabakalı kompozit plaka üretimi gerçekleştirilmiştir. Üretim parametreleri; basınç $20 \mathrm{kN}$, sıcaklık $190^{\circ} \mathrm{C}$ ve süre 300 saniyedir.

Keten/polipropilen tekyönlü prepreg yapılardan; aynı elyaf oranına sahip (\%30) farklı kalınlıklarda (2, 4, $6 \mathrm{~mm})$ düz kompozit plakalar ve aynı kalınlıkta $(3 \mathrm{~mm})$ farkı elyaf oranına sahip (\%30 ve \%50) düz kompozit plakalar elde edilmiştir.

Çalışma kapsamında elde edilen kompozit plakaların detayları Tablo 1'de verilmiştir.

\subsection{Akustik Karakterizasyon}

Çalışma kapsamında üretilen kompozit plakaların akustik performansı, ses yutum katsayısı ve ses iletim kaybı değerleri ile değerlendirilmiştir. Akustik performans testleri, TS EN ISO 10534-2 standardına uygun olarak empedans tüpü ile
1007 
gerçekleştirilmiştir. Ölçüm aralığ $63 \mathrm{~Hz}-8000 \mathrm{~Hz}$ 'dir. Düşük frekanslarda ölçüm için $100 \mathrm{~mm}$ çapında tüp $(50 \mathrm{~Hz}-1500 \mathrm{~Hz})$, yüksek frekanslarda ise $28 \mathrm{~mm}$ çapında tüp $(800 \mathrm{~Hz}-8000 \mathrm{~Hz})$ kullanılmıştır. Tüp çaplarına uygun test numuneler, kompozit plakalardan su jeti ile kesilerek elde edilmiş̧ir. Su jeti işlemi sonrası kompozit plakalar hızlıca tamamen kurutulmuş, laboratuvar ortamında kondüsyonlanmış ve ardından akustik testler yapılmıştır. Kompozit plakalardan elde edilen test numune örnekleri Şekil 2'de verilmiştir.

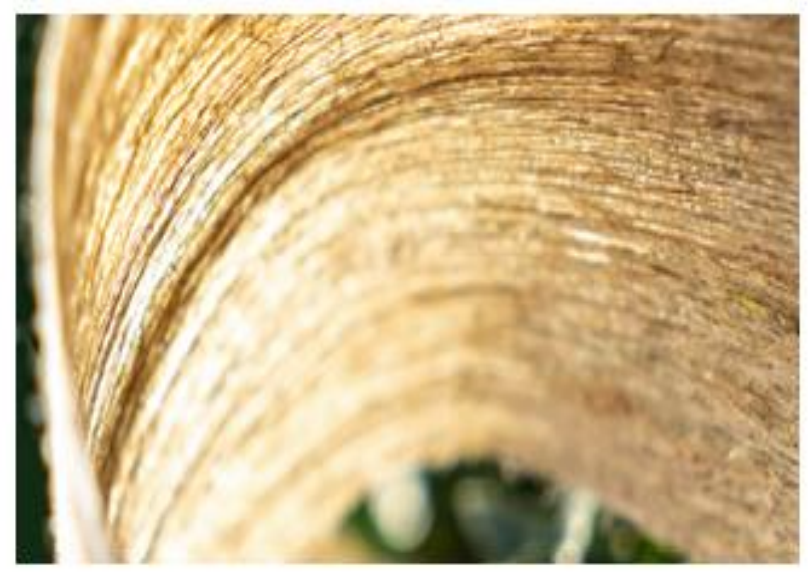

Şekil 1. Keten/Polipropilen Tekyönlü Prepreg Yap1 (EcoRein ${ }^{\circledR}$ UD)

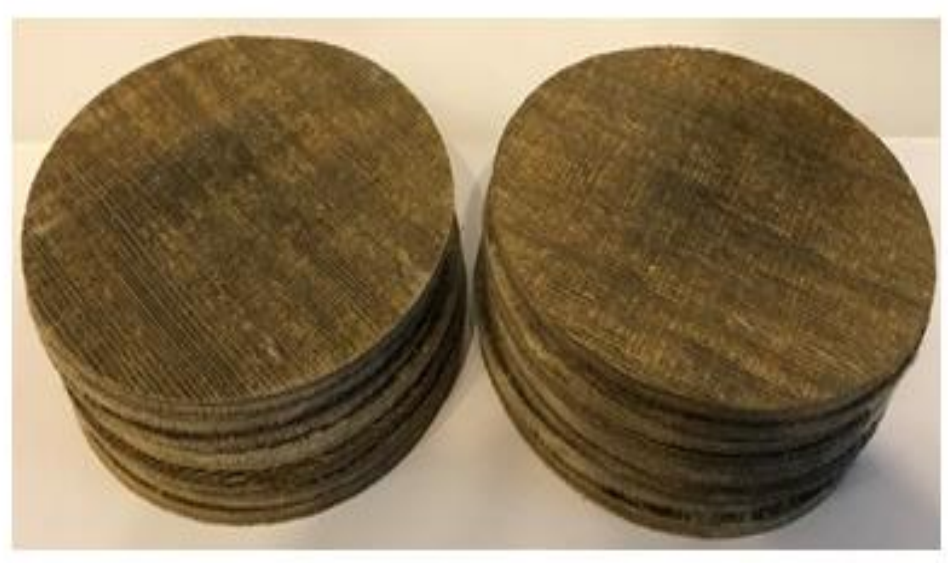

Şekil 2. Akustik Karakterizasyon Test Numuneleri

Tablo 1. Çalışmada Kullanılan Doğal Elyaf Takviyeli Kompozit Malzemeler

\begin{tabular}{|c|c|c|c|c|}
\hline $\begin{array}{l}\text { Numune } \\
\text { Kodu }\end{array}$ & $\begin{array}{l}\text { Keten Elyaf } \\
\text { Oranı* }\end{array}$ & $\begin{array}{l}\text { Kompozit } \\
\text { Plaka Kalınlığı }\end{array}$ & $\begin{array}{l}\text { Kompozit } \\
\text { Plaka Ağırlığı }\end{array}$ & Kompozit Plaka Üretimi \\
\hline 1 & $\% 50$ & $3 \mathrm{~mm}$ & $3.6 \mathrm{~kg} / \mathrm{m}^{2}$ & $\begin{array}{l}12 \text { adet keten/PP tekyönlü prepreg yap1 (EcoRein UD-50) } \\
\text { ile [0/90/0/90/0/90]s diziliminde düz plaka üretilmiştir. }\end{array}$ \\
\hline 2 & $\% 30$ & $3 \mathrm{~mm}$ & $3.0 \mathrm{~kg} / \mathrm{m}^{2}$ & $\begin{array}{l}12 \text { adet keten/PP tekyönlü prepreg yap1 (EcoRein UD-30) } \\
\text { ile }[0 / 90 / 0 / 90 / 0 / 90]_{\text {S }} \text { diziliminde düz plaka üretilmiştir. }\end{array}$ \\
\hline 3 & $\% 30$ & $2 \mathrm{~mm}$ & $2.0 \mathrm{~kg} / \mathrm{m}^{2}$ & $\begin{array}{l}8 \text { adet keten/PP tekyönlü prepreg yapı (EcoRein UD-30) ile } \\
{[0 / 90 / 0 / 90]_{s} \text { diziliminde düz plaka üretilmiştir. }}\end{array}$ \\
\hline 4 & $\% 30$ & $4 \mathrm{~mm}$ & $4.0 \mathrm{~kg} / \mathrm{m}^{2}$ & $\begin{array}{l}2 \text { adet } 3 \text { numuralı kompozit plaka arasına yapışkan bant } \\
\text { konularak } 4 \text { mm'lik düz plaka üretilmiştir. }\end{array}$ \\
\hline 5 & $\% 30$ & $6 \mathrm{~mm}$ & $6.0 \mathrm{~kg} / \mathrm{m}^{2}$ & $\begin{array}{l}3 \text { adet } 3 \text { numuralı kompozit plaka arasına yapışkan bantlar } \\
\text { konularak } 6 \text { mm'lik düz plaka üretilmiştir. }\end{array}$ \\
\hline
\end{tabular}

*A ğırlıkça oranı

\section{Araştırma Sonuçları ve Tartışma}

\subsection{Ses Yutum Katsayısı}

\%30 keten elyaf içeren keten/polipropilen tekyönlü prepreg yapılardan [0/90] dizilim ile 2, 4 ve $6 \mathrm{~mm}$ kalınlığında düz kompozit plakalar elde edilmiş ve ses yutum katsayıları karşılaştırılmıştır. $2 \mathrm{~mm}$ kalınlığındaki kompozit plaka, 8 adet keten/polipropilen tekyönlü prepreg yapıların [0/90] dizilim ile üstüste yerleştirilmesi ve sıcak pres altında kalıplanması ile elde edilmiştir. 4 ve $6 \mathrm{~mm}$ kalınlığındaki kompozit plakalar ise, $2 \mathrm{~mm}$ kalınlığında elde edilen kompozit plakaların arasına yapışkan katman konularak birleştirilmesi ile elde edilmiştir.
Keten elyaf oranları aynı (\% 30) kalınlıkları farklı (2, 4 ve 6 $\mathrm{mm})$ tabakalı kompozit plakaların ses yutum katsayısı değerleri Şekil 3'te verilmiştir.

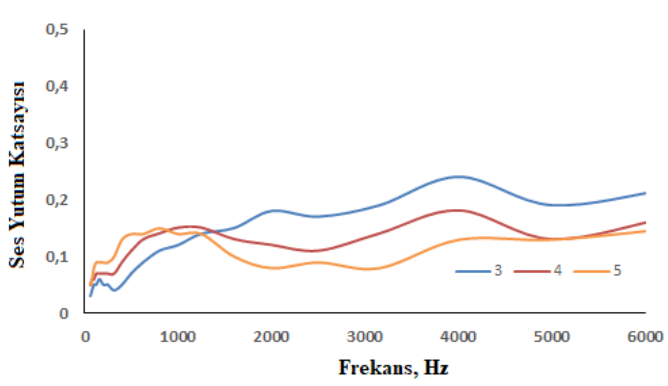

Şekil 3. \%30 keten elyaf içeren 2, 4, ve 6 mm kalınlıkta kompozit plakaların ses yutum katsayısı değerleri

(Numune 3, 4, 5) 
Şekil 3'te verilen değerler incelendiğinde genel anlamda keten/polipropilen tekyönlü prepreg yapılardan elde edilen tabakalı kompozit plakaların ses yutum katsayısının düşük olduğu görülmektedir. Artan plaka kalınlığı, ses yutum katsayısını düşük frekans bölgesinde olumlu etkilerken; yüksek frekans bölgesinde olumsuz etkilemiştir. Gözenekli yapılarda artan plaka kalınlığı ses yutum katsayısını olumlu etkiler. Çalışmaya konu kompozit plakalar da ise artan plaka kalınlığı ses yutum katsayısını olumsuz etkilemiştir. $\mathrm{Bu}$ durum, keten/polipropilen tekyönlü prepreg yapılardan elde edilen tabakalı kompozit plakalarda plaka kalınlığının artması ile olası gözenekli yapının azaldığını ve hatta plakaların kapalı gözenekli yapı sergilediğini işaret etmektedir.

\subsection{Ses İletim Kaybı}

Keten/polipropilen tekyönlü prepreg yapilardan [0/90] dizilim ile aynı elyaf oranına sahip farklı kalınlıklarda düz kompozj plakalarve aynı kalınlıkta farkı elyaf oranına sahip düz kompozit plakar elde edilmiş ve ses yutum katsayıları incelenmiştir. \%30 keten elyaf içeren keten/polipropilen tekyönlü prepreg yapılardan öncelikle $2 \mathrm{~mm}$ kalınlıkta plakalar elde edilmiş ardından $2 \mathrm{~mm}$ kalınlığında elde edilen kompozit plakalarm arasına yapışkan katman konularak 4 ve $6 \mathrm{~mm}$ kalınlıkta plakalar üretilerek; aynı elyaf oranına sahip farklı kalınlıklarda düz kompozit plakalar elde edilmiştir. Aynı oranda (\%30) keten elyaf içeren fakat farklı kalınlıkta üretilen kompozit plakaların se iletim kaybı değerleri Şekil 4'te karşılaştırılmıştır.

$\% 30$ ve $\% 50$ keten elyaf içeren keten/polipropilen tekyönlü prepreg yapılardan her biri $3 \mathrm{~mm}$ kalınlığında düz kompozit plakalar elde edilmiştir. Aynı kalınlıkta $(3 \mathrm{~mm})$ üretilen fakat farklı oranlarda $(\% 30$ ve \%50) keten elyaf içeren kompozit plakaların ses iletim kaybı değerleri Şekil 5'te karşılaştırılmıştır.
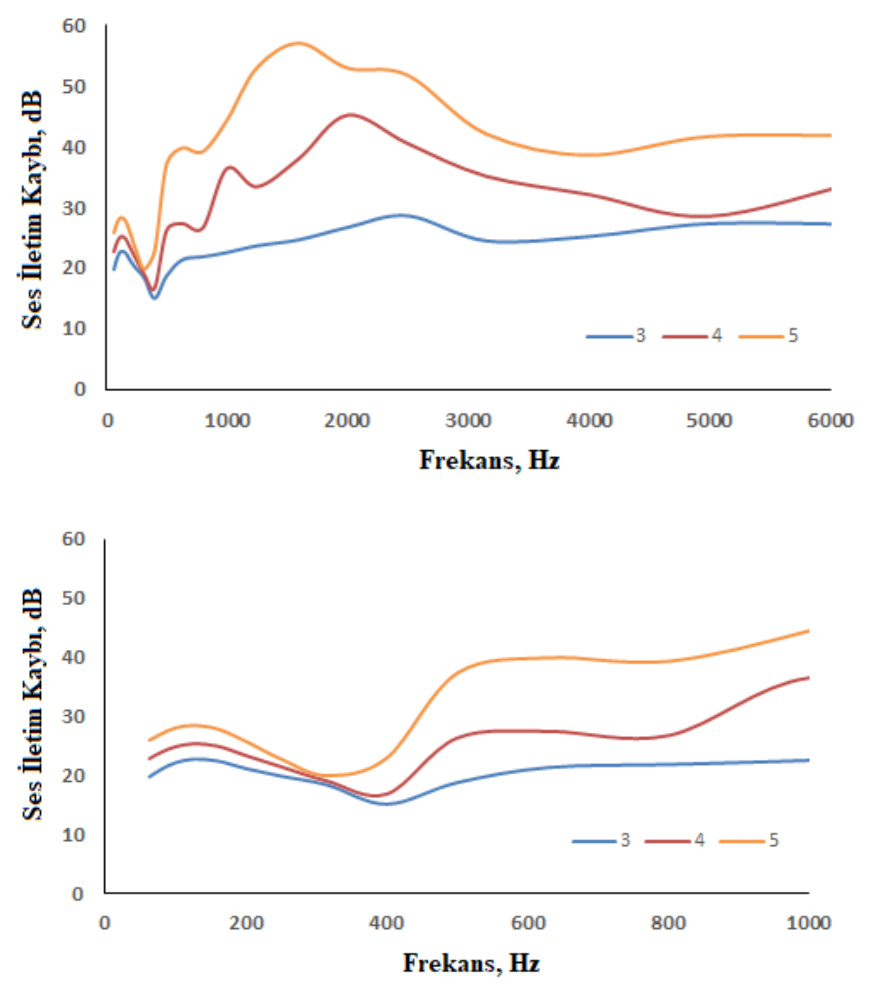

Şekil 4. \%30 keten elyaf içeren 2, 4, ve 6 mm kalınlıkta kompozit plakaların ses iletim kaybı değerleri (Numune 3, 4, 5)

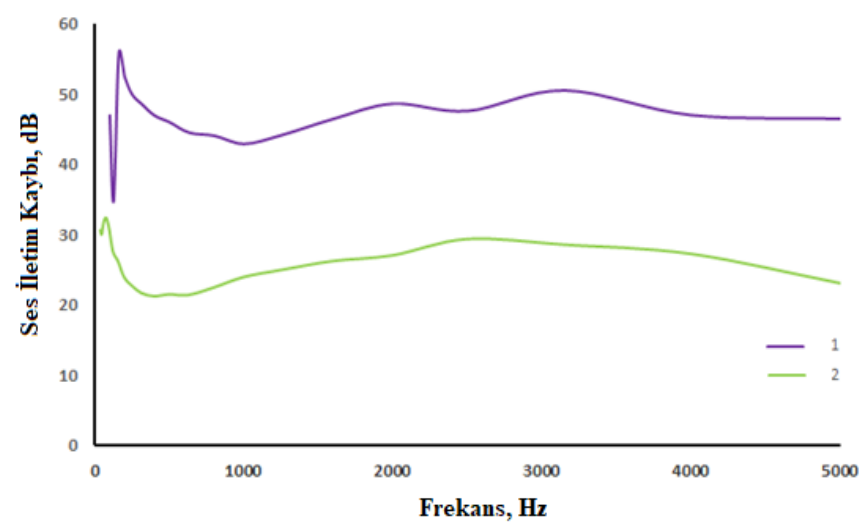

Şekil 5. \%50 ve \%30 keten elyaf içeren $3 \mathrm{~mm}$ kalınlıkta kompozit plakaların ses iletim kaybı değerleri (Numune 1, 2)

Şekil 4 ve Şekil 5 'te verilen değerler incelendiğinde; genel anlamda keten/polipropilen tekyönlü prepreg yapılardan elde edilen tabakalı kompozit plakaların ses iletim kaybı anlamında yüksek performans potansiyeli olduğu açıç̧a görülmektedir.

Keten elyaf oranı aynı olan kompozit plakalarda, artan plaka kalınlığg ile ses iletim kaybı performansının da arttığı gözlenmiştir (Şekil 4). Aynı elyaf oranına sahip kompozit plakalarda, plaka kalınlığına bağlı olarak ses iletim kaybı değerleri; düşük frekans bölgesinde $20-35 \mathrm{~dB}$ arasında değişirken, yüksek frekans bölgesinde ise 40 - $55 \mathrm{~dB}$ arasında değiştiği görülmüştür.

Plaka kalınlığı sabit olan kompozit plakalarda, artan keten elyaf oranı ile ses iletim kaybı değerlerinin de iyileştiği gözlenmiştir (Şekil 5). $3 \mathrm{~mm}$ sabit kalınlıkta üretilen tabakalı kompozit plakalarda keten elyaf içeriğinin \%30 yerine $\% 50$ olması durumunda ses iletim kaybı değerlerinin $30 \mathrm{~dB}$ aralığından $50 \mathrm{~dB}$ aralığına kadar çıkabildiği görülmüştür.

\section{Sonuç}

Ses yutum katsayısı ve ses iletim kaybı değerleri birlikte karşılaştırmalı olarak değerlendirildiğinde; keten/polipropilen tekyönlü prepreg yapılardan elde edilen tabakalı düz kompozit plakaların ses iletim kaybı bakımından yüksek performans gösterdiği ancak ses yutum katsayısı bakımından düşük performans gösterdiği görülmüştür. Alınan test sonuçları, keten/polipropilen tekyönlü prepreg yapılardan elde edilen tabakalı kompozit plakaların düz bir geometride kullanıldığ durumda kapalı gözenekli bir yapı sergilediğini ve bu nedenle hava doğuşlu sesler yerine darbe doğuşlu seslerin izolasyonunda kullanım potansiyeli olduğunu göstermektedir. Keten/polipropilen tekyönlü prepreg yapılardan elde edilecek tabakalı kompozit plakaların, gözenekli yapılar ile birlikte veya düz değil çeşitli geometrilerde kullanımı durumunda hava doğuşlu seslerin izolasyonunda da kullanımı da mümkün olabilir.

Keten/polipropilen tekyönlü prepreg yapılardan üretilecek tabakalı kompozit plakalarda plaka kalınlığı ve/veya keten elyaf oranı arttırılarak ses iletim kaybı değerleri iyileştirilebilmektedir. $40 \mathrm{~dB}$ gibi yüksek oranda ses iletim kaybı değerlerine sahip gürültü bariyerlerini; $3-4 \mathrm{~mm}$ kalınlıkta ve ortalama $4 \mathrm{~kg} / \mathrm{m}^{2}$ ağırlıkta paneller halinde üretmek; keten/polipropilen tekyönlü prepreg yapılar ile mümkün görünmektedir.

$\mathrm{Bu}$ çalışmadan elde edilen sonuçlar, izolasyon sektöründe özellikle gürültü bariyerlerinin üretimi için geri dönüştürülebilir, 


\section{Avrupa Bilim ve Teknoloji Dergisi}

biyo esaslı ve hafif panellerin kullanımının mümkün olduğuna işaret etmektedir.

\section{Teșekkür}

Çalışmamıza gönüllü olarak malzeme ve test desteği sağlayan BPREG Kompozit ve Tekstil A.Ş. ile PECHOM Endüstri ve Makine Ticaret A.Ş. firmalarına teşekkür ederiz.

\section{Kaynakça}

Avérous, L., Le Digabel, F., 2006, Properties of biocomposites based on lignocellulosic fillers, Carbohydrate Polymers, 66(4): 480-493.

Goutianos, S., Peijs, T., Nystrom, B., Skrifvars, M., 2006, Development of flax fibre based textile reinforcements for composite applications, Applied Composite Materials, 13(4): 199-215.

Grohe, B., 2004, Heat conductivities of insulation mats based on water glass bonded non-textile hemp or flax fibres, Holz als Roh- und Werkstoff, 62(5): 352-357.

Hajj, N.E., Mboumba-Mamboundou, B., Dheilly, R.-M., Aboura, Z., Benzeggagh, M., Queneudec, M., 2011, Development of thermal insulating and sound absorbing agro-sourced materials from auto linked flax-tows, Industrial Crops and Products, 34(1): 921-928.

Hautala, M., Pasila, A., Pirilä, J., 2004, Use of hemp and flax in composite manufacture: A search for new production methods, Composites Part A: Applied Science and Manufacturing, 35(1): 11-16.

Holbery, J., Houston, D., 2006, Natural-fiber-reinforced polymer composites in automotive applications, JOM, 58(11): 8086.

Kymäläinen, H.-R., Sjöberg, A.-M., 2008, Flax and hemp fibres as raw materials for thermal insulations, Building and Environment, 43(7): 1261-1269.

Liu, Q., Stuart, T., Hughes, M., Sharma, H.S.S., Lyons, G., 2007, Structural biocomposites from flax - part ii: The use of peg and pva as interfacial compatibilising agents, Composites Part A: Applied Science and Manufacturing, 38(5): 1403-1413.

Martin, N., Davies, P., Baley, C., 2014, Comparison of the properties of scutched flax and flax tow for composite material reinforcement, Industrial Crops and Products, 61(0): 284-292.

Martin, N., Davies, P., Baley, C., 2016, Evaluation of the potential of three non-woven flax fiber reinforcements: Spunlaced, needlepunched and paper process mats, Industrial Crops and Products, 83: 194-205.

Misnon, M.I., Islam, M.M., Epaarachchi, J.A., Lau, K.-t., 2014, Potentiality of utilising natural textile materials for engineering composites applications, Materials \& Design, 59(0): 359-368.

Nick, A., Becker, U., Thoma, W., 2002, Improved acoustic behavior of interior parts of renewable resources in the automotive industry, Journal of Polymers and the Environment, 10(3): 115-118.

Shah, D.U., Schubel, P.J., Licence, P., Clifford, M.J., 2012, Determining the minimum, critical and maximum fibre content for twisted yarn reinforced plant fibre composites, Composites Science and Technology, 72(15): 1909-1917.

Stuart, T., Liu, Q., Hughes, M., McCall, R.D., Sharma, H.S.S., Norton, A., 2006, Structural biocomposites from flax- part i: Effect of bio-technical fibre modification on composite properties, Composites Part A: Applied Science and Manufacturing, 37(3): 393-404.

Summerscales, J., Virk, A., Hall, W., 2013, A review of bast fibres and their composites: Part 3 - modelling, Composites Part A: Applied Science and Manufacturing, 44(0): 132139.

Yan, L., Chouw, N., Jayaraman, K., 2014, Flax fibre and its composites - a review, Composites Part B: Engineering, 56(0): 296-317.

Yang, W., Li, Y., 2012, Sound absorption performance of natural fibers and their composites, Science China Technological Sciences, 55(8): 2278-2283.

Zimniewska, M., Myalski, J., Koziol, M., Mankowski, J., Bogacz, E., 2012, Natural fiber textile structures suitable for composite materials, Journal of Natural Fibers, 9(4): 229-239. 